\title{
Comparison of extraction methods for evaluating antioxidant and antibacterial properties of Vernonia amygdalina leaves extract
}

\author{
Muharni Muharni *, Elfita Elfita, Heni Yohandini and Chika Valenta \\ Department of Chemistry, Faculty of Mathematics and Natural Sciences, University of Sriwijaya, Indralaya, \\ Ogan Ilir, South Sumatra, 30662 Indonesia
}

\begin{abstract}
In this study, we were interested in comparing the influence of different extraction methods on antioxidant and antibacterial activities of V.amygdalina leaves extracts. The extracts were also analyzed for their total phenolic and flavonoid content. The extraction methods used maceration, soxhlet, and fractionation, the evaluation of antioxidant activity using DPPH (1,1-diphenyl-2-picryl-hydrazyl) method and antibacterial activity by agar diffusion method. The total phenolic and flavonoids are determined by the spectrophotometric method. Ethanol extract by fractionating on this method showed the highest antioxidant properties compared to other extracts with $\mathrm{IC}_{50} 170 \mu \mathrm{g} / \mathrm{mL}$ in category potent antioxidant with total phenolic content $28.83 \pm 2.62 \mathrm{mg} \mathrm{GAE} / \mathrm{g}$, and the total flavonoid content $18.78 \pm 0.15 \mathrm{mg}$ QE/g. Evaluation of antibacterial properties the extracts of $V$. amyigdalina showed moderate antibacterial activity against all bacteria tests with inhibition zone $6.1 \pm 0.1$ to 9.4 $\pm 0.9 \mathrm{~mm}$ at variation concentration $62.5-1000 \mu \mathrm{g} / \mathrm{mL}$. The fractionation method using ethanol solvent is the best for the extraction of antioxidant compounds from $V$. amygdalina.
\end{abstract}

Keywords: Antioxidant; antibacterial; phenolic; flavonoids; Vernonia amigdalina.

\section{Introduction}

The selection of the extraction method is one of the decisive steps in the research for obtaining bioactive compounds from natural materials. Usually, the solute extracted is insoluble or slightly soluble in one solvent but easily dissolves with other solvents ${ }^{1}$. The effectivity of extraction depends on the experimental conditions applied, such as extraction time, type of extraction, and solvent used. The extraction method and solvent used determine the discovery of bioactive compounds from medicinal plants. Based on the literature studies, the research showed differences in biological activities from the extracts of plants, depending upon the extraction methods and solvents used. Optimation of the extraction process was required to obtain bioactive compounds. Marugan and Thangaraj ${ }^{2}$ report at extracts of Osbeckia parvifolia showed the highest antioxidant by the maceration method compared to soxhlet extraction.

One traditional medicine is $V$. amigdalina which belongs to the family Asteraceae and in Indonesia is known as the insulin leaf ${ }^{3}$. V.amigdalina is distributed in tropical and subtropical regions of Africa, Asia, and America. In southern Sumatra, especially at the Musi banyuasin, people have traditionally used this plant to treat diabetes. These plants are used as traditional medicines for anti-

*Corresponding author: Muharni Muharni

Email address: muharnimyd@yahoo.co.id

DOI: http://dx.doi.org/10.13171/mjc10802009101498mm inflammatory, rheumatism, antimalarial, diarrhea, intestinal diseases, diabetes, and amoebiasis ${ }^{4}$. The use of $V$. amigdalina as traditional medicine was related to the chemical content of antioxidants and antibacterials of extract.

Biological activity of $V$. amygdalina species has been reported as antimicrobial 5, antitumor 6,7, anticancer 8,9 anti-inflammatory ${ }^{10}, \quad$ and antidiabetic ${ }^{11}$. Extracts of the leaves of $\mathrm{V}$. amygdalina contain flavonoid compounds, which are secondary metabolites to act as antioxidant ${ }^{12}$. Various chemical compounds that have been found in the leaves of $V$. amygdalina include flavonoid Luteolin 7-O-B-glucoronoside, Luteolin 7-O-Bglucoside, and Luteolin. The leaves extract of $V$. amigdalina also has been reported to contain compounds of sesquiterpene vernolida, and veodanol. These compounds are shown active against gram-positive and two-gram negative bacteria ${ }^{13}$. In this research, we reported the comparison extraction methods for evaluating antioxidant and antibacterial properties of Vernonia amygdalina leaves extract. Extraction according to three methods: maceration, soxhlet, and fractionation with ethanol and ethyl acetate as solvent.

\section{Experimental}

\subsection{Chemicals}

Received June 10, 2020

Accepted August 7, 2020

Published September 10, 2020 
The chemical used was ethanol p.a, ethyl acetate p.a, methanol p.a $\left(\right.$ Merck $\left.^{\circledR}\right)$, DPPH (1,1-diphenyl-2picryl-hydrazyl) $\left(\right.$ Sigma-Aldrich $\left.^{\circledR}\right)$, ascorbic acid, DMSO (dimethyl sulfoxide), gallic acid, quercetin, folin ciochalteu, sodium carbonate, aluminum chloride $10 \%$, potassium acetate, $\mathrm{CH}_{3} \mathrm{COOK}$ $\left(\right.$ Merck $\left.^{\circledR}\right)$, distilled water, NA (nutrient agar), NB (nutrient broth) (Sigma-Aldrich $\left.{ }^{\circledR}\right)$, Escherichia coli (ATCC 25922), Staphyloccocus aureus (ATCC 25923), Bacillus subtilis (ATCC 6633), and Shigella dysenteriae (ATCC 23354) (Bio farma), tetracycline (Bio farma). All chemicals and solvents used were of analytical grade.

\subsection{Instrumentation}

The instrumentation used for the studies is soxhlet devices, UV-Vis spectrophotometry (Beckman Coulter), rotary evaporators (Scilogex RE100-Pro), laminar airflow, incubators, autoclaves, analytical balances (Ohaus ${ }^{\circledR}$ ), UV lamps (CAMAG).

\subsection{Plant material}

The leaves of V. Amygdalina were collected during February 2019 from Indralaya Ogan Ilir South Sumatera, Indonesia. This plant has been the identification, and plant voucher specimens deposited in Herbarium Andalas (ANDA), Departement of Biology, Faculty of Mathematics and Natural Sciences, Andalas University, West Sumatera, Indonesia. The leaves of $V$. amygdalina were cleaned and cut in small pieces and then were extracted by three methods: maceration, soxhlet, and fractionation with two solvents, ethanol, and ethyl acetate Bio Farma.

\subsection{Extraction}

\subsubsection{Maceration}

The leaves $V$. amygdalina (small pieces) each $100 \mathrm{~g}$ was taken in a conical flask and extracted with $500 \mathrm{~mL}$ organic solvent (ethyl acetate and ethanol) at room temperature for 24 hours. The filtrate was filtered using filter paper Whatman 42 . The filtrate was evaporated under vacuum in a rotary evaporator at $50^{\circ} \mathrm{C}$ to obtain concentrated ethyl acetate and ethanol extracts, and each extract determined the yield percentage.

\subsubsection{Soxhlet}

The leaves of $V$. amyigdalina (small pieces) each $100 \mathrm{~g}$ were prepared to extraction using soxhlet equipment (solvent: ethyl acetate and ethanol) with a ratio of $5: 1(\mathrm{~mL} / \mathrm{g})$ for 6 hours at temperature $70^{\circ} \mathrm{C}$. The filtrate obtained was evaporated using a rotary evaporator at $50^{\circ} \mathrm{C}$, and The residue obtained determined the yield percentage.

\subsubsection{Fractionation}

$200 \mathrm{~g}$ of plant material extracted left for 24 hours with ethanol in the maceration method. The extraction was repeated three times until complete extraction. A rotary vacuum evaporator evaporated the filtrate. The crude ethanol extract further extracted was organic solvent ethyl acetate and after evaporating to obtain concentrated ethyl acetate extract and ethanol extract. The yield percentage determined each extract.

\subsection{Water content}

The water content was determined by weighed $1-2 \mathrm{~g}$ of the extract carefully and dried it at $105^{\circ} \mathrm{C}$ for 4 hours then weighed. The drying process was continued for 1 hour and considered until the difference between the last 2 weighings were not more than $0.25 \%{ }^{14}$

\subsection{Antioxidant Activity Analysis using DPPH Method}

The antioxidant activity of the extracts was tested by DPPH method ${ }^{15}$. The solution of DPPH (1,1-diphenyl-di-picrylhydrazyl) at $0.05 \mathrm{mM}$ is obtained by dissolving $1.98 \mathrm{mg}$ of the DPPH powder in $100 \mathrm{~mL}$ methanol. The donating ability of the hydrogen atom of the plant extractives was determined by the decolorization of solution 2,2-diphenyl-1-picrylhydrazyl (DPPH) from violet/ purple color into yellow color in the presence of antioxidants. The extract samples at various concentrations $\quad(1000 ; 500 ; 250 ; 125 ;$ and $62.5 \mu \mathrm{g} / \mathrm{mL}$ ) and standard antioxidant ascorbic acid $(100 ; 50 ; 25 ; 12.5$; and $6.25 \mu \mathrm{g} / \mathrm{mL})$ were prepared. The test was carried out by mixing $0.2 \mathrm{~mL}$ of sample or standard at different concentrations with $3.8 \mathrm{~mL}$ $0.05 \mathrm{mM}$ DPPH solution. The positive control consists $5 \mathrm{~mL}$ of DPPH solution without extract. The reaction mixtures were vortexed and incubated for $30 \mathrm{~min}$ in the dark at room temperature. The absorbance was measured using spectrophotometer UV-Vis at $517 \mathrm{~nm}$. As blanks used methanol. Radical scavenging activity against DPPH was calculated as a percentage of inhibition, according to the following formula:

$\%$ DPPH radical scavenging activity $=\left\{\left(\mathrm{A}_{0}-\mathrm{A}_{1}\right) /\right.$ $\left.\mathrm{A}_{0}\right\} \times 100$

where A0 is the absorbance of the control, and A1 is the absorbance of the extractives/standard. Then $\%$ of inhibition was plotted against concentration, and from the graph, $\mathrm{IC}_{50}$ was calculated. The experiment was repeated three times at each concentration.

\subsection{Antibacterial Activity of Extracts}

The antibacterial activity of the formula extracts was measured by the Paper disc agar diffusion method on strains of Escherichia coli (ATCC 25922), Staphyloccocus aureus (ATCC 25923), Bacillus subtilis (ATCC 6633), and Shigella dysenteriae (ATCC 23354). An aliquot of $10 \mu \mathrm{L}$ of the extract evaluated $(1000,500,150,62,5 \mu \mathrm{g} / \mathrm{mL})$ of each extract was applied to sterile filter paper discs (Whatman no. 1; $6 \mathrm{~mm}$ in diameter). The discs were placed on the medium nutrient agar (NA) plates previously seeded with the tested bacteria culture as control used standard antibacterial tetracycline susceptibility discs (10 $\mu \mathrm{g} / \mathrm{disc})$. In comparison, $10 \mu \mathrm{L}$ of dimethyl sulfoxide (DMSO) was included 
as negative control. The plates were then incubated for $24 \mathrm{~h}$ at $37^{\circ} \mathrm{C}$. The antibacterial activity was evaluated by measuring the diameter of inhibition zones. All samples were analyzed in triplicate, and the means of inhibition zone diameters were determined $^{16,17}$.

\subsection{Determination of total phenolic and flavonoid content}

The total phenolic content was determined according to the base on the modification method described ${ }^{18-20} .5 \mathrm{mg}$ of each sample of different extracts were dissolved in $2 \mathrm{~mL}$ ethanol, and the volume was made up to a volume of $5 \mathrm{~mL}$ with distilled water. Each standard and sample was added $0.5 \mathrm{~mL}$ of $50 \%$ folin ciocalteu's phenol reagent (1:1 with water) and incubated for 5 minutes. Then, $1 \mathrm{~mL}$ sodium carbonate solution $(5 \%)$, and the liquid was homogenized. The reaction tube was placed at room temperature for 1 hour. The absorbance was recorded using spectrophotometer UV-Vis at wavelength $725 \mathrm{~nm}$, as a reagent blank used the mixture reaction without sample. A calibration curve is carried out in parallel under the same operating conditions using gallic acid as a positive control with a concentration of $5,10,15,20 \mu \mathrm{g} / \mathrm{mL}$. The amount of total phenolic of each extract was calculated as milligrams (mg) equivalent of gallic acid per gram of dry plant (mg GAE/g).

The flavonoid content of extracts was determined according to the method described ${ }^{20-23}$. Each extract and the standard solution were added to $1.5 \mathrm{~mL}$ of methanol, $0.1 \mathrm{~mL}$ of aluminum chloride $10 \%, 1 \mathrm{~mL}$ of sodium nitrate $1 \mathrm{M}$, and $2.8 \mathrm{~mL}$ of distilled water. The liquid was homogenized using the vortex, incubated for 30 minutes, and measured using spectrophotometer UV-Vis at $415 \mathrm{~mm}$. A calibration curve is carried out in parallel under the same operating conditions using quercetin as a positive control with a concentration of 50,100,150, and $200 \mu \mathrm{g} / \mathrm{mL}$. The amount of flavonoid content each extract was calculated as milligrams $(\mathrm{mg})$ equivalent of quercetin per gram of dry plant (mg GAE/g).

\subsection{Data analysis}

Quantitative data obtained were analyzed descriptively. For the measurement with three measurements, data are given as the mean \pm SD. Data was statistical analysis ANOVA alfa 0.05, followed by Duncan New Multiple Range Test (DNMRT) test at alfa 0.05 .

\section{Results and Discussion}

\subsection{Determination yield percentage extract}

Biologically active compounds usually occur in low concentrations in plants. So the choice of extraction method is necessary for the amount extracts obtained with high yield ${ }^{24}$. Several studies reported the use of different extraction methods and solvent showed a result that the biological activities are different. Therefore, it is necessary to select suitable extraction methods as well as solvents based on the desired properties ${ }^{25}$. The leaves of $V$. Amigdalina were extracted by three extraction methods maceration, soxhlet, and fractionation, with two solvents (ethanol and ethyl acetate), respectively. Each extract obtained was determined yield percentage and water content, antioxidant and antibacterial activity, and the total phenolic and flavonoid contents. The yield percentage is a measure of the solvent effective to extract specific compounds from the material. The result of the yield percentage of each extract is shown in Table 1 . The yield percentage of the extract obtained at the maceration method with the ethanol solvent to give the highest value than the soxhlet and fraction method with a value of $3.23 \%$. Statistical analysis showed that the different solvents had a significant effect on yield percentage $(\mathrm{p}<0.05)$. Statistical analysis for the extraction, the maceration, and fractionation methods showed no considerable difference for ethanol solvent. Still, the ethyl acetate solvent showed a significant difference in yield percentage among all extraction methods.

Table 1. Yield Percentage of extracts.

\begin{tabular}{|c|c|c|c|}
\hline \multirow{2}{*}{ Solvent } & \multicolumn{3}{|c|}{ Yield percentage \pm SD } \\
\cline { 2 - 4 } & Maceration & Soxhlet & $3.15 \pm 0.33^{\mathrm{b}}$ \\
\hline Ethanol & $3.23 \pm 0.62^{\mathrm{b}}$ & $1.28 \pm 0.11^{\mathrm{a}}$ & $1.12 \pm 0.17$ \\
\hline Ethyl acetate & $2.06 \pm 0.21$ & $2.48 \pm 0.17$ \\
\hline
\end{tabular}

Numbers followed by the same subscript indicate not significantly different, SD: Standard deviation

\subsection{Determination of the water content}

The total water content in each extract was analyzed and showed in Table 2. Based on these data, ethanol extract in the maceration method offers the highest water content $(21.46 \%)$ compared to other methods. For ethyl acetate extract, the water content in maceration also to highest $(15.57 \%$. Based on the Indonesian Ministry of Health, the limit allowed for water content in extract $<10 \%{ }^{14}$. The result of determination showed only ethyl acetate extract by soxhlet, which has water content $<10 \%(7.4 \%)$. The water content of the other extracts from leaves the $V$. amygdalina was exceeding the water content limit allowed in the extract, so the extract must be dried before usage to prevent microbial contamination. The statistical analysis showed the Soxhlet method with ethyl acetate solvent had a significant difference in the percentage of water content $(p<0.05)$ compared to other methods. 
Table 2. Precentage water content of extracts $V$. Amigdalina.

\begin{tabular}{|c|c|c|c|}
\hline \multirow{2}{*}{ Solvent } & \multicolumn{3}{|c|}{ Percentage of water content \pm SD } \\
\cline { 2 - 4 } & Maceration & Soxhlet & Fractionation \\
\hline Ethanol & $21.46 \pm 0,07$ & $15.16 \pm 0.01^{\mathrm{a}}$ & $17.15 \pm 0.33$ \\
\hline Ethyl acetate & $15.57 \pm 0,04^{\mathrm{a}}$ & $7.40 \pm 0.06$ & $12.52 \pm 0.26$ \\
\hline
\end{tabular}

Numbers followed by the same subscript indicate not significantly different, SD: Standard deviation

\subsection{Antioxidant activity}

The biological activities of the extracts of plants showed differences, depending upon the extraction methods and solvents used. The extracts of Osbeckia parvifolia showed high antioxidant by the maceration method compared to soxhlet extraction ${ }^{2}$. The antioxidant activity of V. amigdalina extracts was determined by the DPPH method ${ }^{15}$. This method is generally used for the evaluation of the antioxidant activity of various plant extracts. The antioxidant activity of different solvent extracts and extraction method were measured and shown in Table 3 and as compound standart antioxidant used ascorbic acid.
The reduction of this radical is accompanied by its change from the purple, characteristic of the DPPH solution, to yellow (DPPH-H). The percentage of DPPH inhibition value increases with increasing sample concentration. At the same concentration $1000 \mu \mathrm{g} / \mathrm{mL}$, the ethanol extract with the fractionation method shows an inhibition percentage higher than other extracts with an inhibition percentage of $92.65 \%$. Extraction using ethyl acetate solvent also showed the highest percentage inhibition for the fractionation method compared to other methods. This indicated that the extract with a small mixture of components has higher antioxidant properties than the more complex extract.

Table 3. The influence of concentration on DPPH inhibition of V. Amigdalina extracts ethanol and ethyl acetate with maceration and soxhlet method.

\begin{tabular}{|c|c|c|c|c|c|c|}
\hline \multirow{3}{*}{$\begin{array}{l}\text { Concentration } \\
(\mu \mathrm{g} / \mathrm{mL})\end{array}$} & \multicolumn{6}{|c|}{ Inhibition percentage $(\% \mathrm{I}) \pm \mathrm{SD}$} \\
\hline & \multicolumn{2}{|c|}{ Maceration } & \multicolumn{2}{|c|}{ Soxhlet } & \multicolumn{2}{|c|}{ Fractionation } \\
\hline & Ethanol & Ethyl acetate & Ethanol & Ethyl acetate & Ethanol & Ethyl acetate \\
\hline 1000 & $88.05 \pm 3.14$ & $63.34 \pm 0.15$ & $89.78 \pm 0.15$ & $65.76 \pm 0.15$ & $92.65 \pm 0.15$ & $74.15 \pm 0.15$ \\
\hline 500 & $44.30 \pm 2.66$ & $50.18 \pm 1.90$ & $45.00 \pm 2.03$ & $52.92 \pm 2.22$ & $67.56 \pm 7.57$ & $60.21 \pm 2.40$ \\
\hline 250 & $38.16 \pm 0.97$ & $36.60 \pm 3.38$ & $22.75 \pm 2.81$ & $23.79 \pm 2.30$ & $59.15 \pm 2.20$ & $48.02 \pm 3.27$ \\
\hline 125 & $25.45 \pm 1.41$ & $19.54 \pm 2.54^{\mathrm{a}}$ & $20.12 \pm 1.92$ & $18.40 \pm 1.58$ & $49.55 \pm 2.94$ & $32.91 \pm 4.78$ \\
\hline 62.5 & $15.13 \pm 0.79$ & $18.35 \pm 0.81^{\mathrm{a}}$ & $11.56 \pm 1.82$ & $10.22 \pm 1.29$ & $37.51 \pm 1.56$ & $21.25 \pm 1.62$ \\
\hline
\end{tabular}

Numbers followed by the same subscript indicate not significantly different, SD: Standard deviation

Based on the inhibition percentages, value was calculated the value of $\mathrm{IC}_{50}$. The $\mathrm{IC}_{50}$ value for $V$. amygdalina extracts was determined by linear regression from $\%$ of inhibition was plotted against concentration. Table 3 showed the ethanol extract with the fractionation method, which has the strongest anti-free radical activity $\left(\mathrm{IC}_{50} 170 \mu \mathrm{g} / \mathrm{mL}\right)$; meanwhile, ascorbic acid used as a standard gives an $\mathrm{IC}_{50}$ value $9.0 \mu \mathrm{g} / \mathrm{mL}$. Data in Table 4 showed The difference solvent using extraction effects on the $\mathrm{IC}_{50}$ value of extracts. Extraction using ethanol solvent shown $\mathrm{IC}_{50}$ is higher for all methods extraction compared to ethyl acetate solvent. The extract is categorized as a potent antioxidant if it has an $\mathrm{IC}_{50}$ of less than $200 \mu \mathrm{g} / \mathrm{mL}$. The $\mathrm{IC}_{50}$ value around 200 to $1000 \mu \mathrm{g} / \mathrm{mL}$ in the moderate antioxidant category, and above $1000 \mu \mathrm{g} / \mathrm{mL}$ were categorized as inactive 26. For pure compounds are classified as a strong antioxidant if they have an $\mathrm{IC}_{50}$ less than $10 \mu \mathrm{g} / \mathrm{mL}$, 10 to $100 \mu \mathrm{g} / \mathrm{mL}$ in the moderate antioxidant category, and above $100 \mu \mathrm{g} / \mathrm{mL}$ in categorized as inactive. Based on data $\mathrm{IC}_{50}$ obtained, only ethanol extract from the fractionation method in the potent category antioxidant and other extracts in the category moderate antioxidant $\left(\mathrm{IC}_{50}\right.$ value 200 to $1000 \mu \mathrm{g} / \mathrm{mL}$ ). Extracts with the moderate antioxidant category are still potential as a source of antioxidant compounds ${ }^{13}$. Based on this data, ethanol extract with the fractionation method of the leaves of $V$. amygdalina can be used as a source of antioxidant compounds. 
Table 4. Inhibition concentrations of $50 \%$ of DPPH•

\begin{tabular}{|c|c|c|c|}
\hline \multirow{2}{*}{ Solvent } & \multicolumn{3}{|c|}{ IC50 $(\boldsymbol{\mu g} / \mathbf{m L})$} \\
\cline { 2 - 4 } & Maceration & Soxhlet & Fractionation \\
\hline Ethyl acetate & 640 & 650 & 350 \\
\hline Ethanol & 490 & 530 & 170 \\
\hline
\end{tabular}

\subsection{Antibacterial activity}

The response to the inhibition of bacterial growth by the extracts was characterized by the inhibition zone's presence around the disc paper. Antibacterial activity was done on three extraction methods using ethanol and ethyl acetate solvent with positive control groups (Tetracycline $\mathrm{HCl}$ ) and negative controls (DMSO 10\%). The result Antibacterial activity test showed that most of the extracts showed antibacterial activity against test bacteria both for ethanol and ethyl acetate extract. The test using the disc diffusion method with inhibition zones ranging from $6.1 \pm 0.1$ to $9.4 \pm 0.9 \mathrm{~mm}$ at variation concentration $62.5-1000 \mu \mathrm{g} / \mathrm{mL}$ ) (Tables 5 and 6). However, the antibacterial activity of extract weaker compared tetracycline at concentration $10 \mu \mathrm{g} /$ disc (inhibition zone, all bacterial test $15.7 \pm 0,6$ to $19.7 \pm 0.3 \mathrm{~mm}$ ). The antibacterial activity of the extract against $B$. subtilis and $S$. dysenteriae is weaker compared to antibacterial activity against $E$. coli and $S$. aureus. The DMSO as negative control showed no inhibition zone around the disc paper.
Data in Tables 5 and 6 also show that the higher the concentration of extract, the larger the inhibition zone's diameter. Ethanol and ethyl acetate extracts more inhibited $E$. coli and $S$. aureus bacteria compared to $B$. subtilis and $S$. dysenteriae. However, extraction by fraction showed higher antibacterial activity against Bacillus and $S$. dysenteriae bacteria than maceration and soxhlet extraction methods. This is because the fractionation method has a mixture compound in the extract. It is simple than maceration and soxhletation methods so that the concentration of the active compounds is higher, and the activity is more substantial. Antibacterial activity characteristics were classified into three categories, strong activity with inhibition zone diameter of 10-20 mm, moderate activity with an inhibition zone of 5-10 mm, and weak activity with inhibition zone $<5 \mathrm{~mm}^{27}$. Based on this category, the extracts of $V$. amygdalina were categorized as providing moderate antibacterial activity against all bacteria test.

Table 5. Antibacterial activity of ethanol extracts the leaves of V. amigdalina.

\begin{tabular}{|c|c|c|c|c|c|}
\hline \multirow{2}{*}{$\begin{array}{c}\text { Extraction } \\
\text { method }\end{array}$} & \multirow{2}{*}{$\begin{array}{c}\text { Concentration } \\
(\mu \mathrm{g} / \mathrm{mL})\end{array}$} & \multicolumn{4}{|c|}{ zone of inhibition $(\mathrm{mm}) \pm \mathrm{SD}$} \\
\hline & & E. coli & S. aureus & B. subtilis & S. dycentriae \\
\hline \multirow[t]{5}{*}{ Maceration } & 1000 & $9.4 \pm 0.9$ & $7.2 \pm 0.6$ & $6.7 \pm 0.5$ & $7.5 \pm 0.6$ \\
\hline & 500 & $7.9 \pm 1.1$ & $6.8 \pm 0.2$ & $6.2 \pm 0.1$ & $6.4 \pm 0.3$ \\
\hline & 250 & $9.2 \pm 1.1$ & $6.6 \pm 0.1$ & $\mathrm{NI}^{*}$ & NI* \\
\hline & 125 & $7.3 \pm 1.2$ & $6.4 \pm 0.1$ & $\mathrm{NI}^{*}$ & $\mathrm{NI} *$ \\
\hline & 62.5 & $7.2 \pm 1.2$ & $6.2 \pm 0.1$ & NI* & NI* \\
\hline \multirow[t]{6}{*}{ Soxhlet } & 1000 & $7.2 \pm 0.3$ & $8.8 \pm 1.8$ & $6.8 \pm 0.1$ & $6.2 \pm 0.1$ \\
\hline & 500 & $7.1 \pm 0.4$ & $7.5 \pm 0.3$ & NI* & NI* \\
\hline & 250 & $6.8 \pm 0.3$ & $6.3 \pm 0.1$ & $\mathrm{NI}^{*}$ & $\mathrm{NI} *$ \\
\hline & 125 & $6.4 \pm 0.2$ & $6.2 \pm 0.2$ & $\mathrm{NI}^{*}$ & $\mathrm{NI} *$ \\
\hline & 62.5 & $6.3 \pm 0.1$ & $6.2 \pm 0.2$ & $\mathrm{NI}^{*}$ & $\mathrm{NI}^{*}$ \\
\hline & 1000 & $7.1 \pm 0.5$ & $7.6 \pm 0.1$ & $7.1 \pm 0.1$ & $7.1 \pm 0.1$ \\
\hline \multirow[t]{4}{*}{ Fracination } & 500 & $6.4 \pm 0.1$ & $7.5 \pm 0.1$ & $6.9 \pm 0.1$ & $6.9 \pm 0.1$ \\
\hline & 250 & $6.3 \pm 0.1$ & $7.1 \pm 0.1$ & $6.5 \pm 0.1$ & $6.5 \pm 0.1$ \\
\hline & 125 & $6.3 \pm 0.1$ & $6.9 \pm 0.4$ & $6.4 \pm 0.2$ & $6.4 \pm 0.2$ \\
\hline & 62.5 & $6.2 \pm 0.2$ & $6.4 \pm 0.2$ & $\mathrm{NI}^{*}$ & $\mathrm{NI}^{*}$ \\
\hline Standart & & $16.7 \pm 0.3$ & $15.7 \pm 0.6$ & $19.7 \pm 0.3$ & $17.7 \pm 0.6$ \\
\hline Control & & $\mathrm{NI}^{*}$ & $\mathrm{NI}^{*}$ & NI* & $\mathrm{NI}^{*}$ \\
\hline
\end{tabular}

Control (DMSO), Standard: tetracyclin $(10 \mu \mathrm{g} / \mathrm{disc}),{ }^{*}$ NI: No inhibition zone, Values were expressed as mean 
Table 6. Antibacterial activity of ethyl acetate extracts the leaves of V. Amigdalina.

\begin{tabular}{|c|c|c|c|c|c|}
\hline \multirow{2}{*}{$\begin{array}{l}\text { Extraction } \\
\text { method }\end{array}$} & \multirow{2}{*}{$\begin{array}{c}\text { Concentration } \\
((\mu \mathrm{g} / \mathrm{mL}))\end{array}$} & & \multicolumn{3}{|c|}{ Zone of inhibition $(\mathrm{mm}) \pm \mathrm{SD}$} \\
\hline & & E. coli & S. aureus & B. subtilis & S. dycentriae \\
\hline \multirow[t]{5}{*}{ Maceration } & 1000 & $8.1 \pm 0.1$ & $7.6 \pm 0.4$ & $8.3 \pm 0.3$ & $7.2 \pm 1.1$ \\
\hline & 500 & $7.7 \pm 0.5$ & $7.2 \pm 0.7$ & $7.4 \pm 0.2$ & $6.8 \pm 0.6$ \\
\hline & 250 & $7.7 \pm 0.5$ & $7.1 \pm 0.6$ & $6.7 \pm 0.2$ & $6.1 \pm 0.1$ \\
\hline & 125 & $7.5 \pm 0.5$ & $6.8 \pm 0.9$ & $6.4 \pm 0.1$ & NI* \\
\hline & 62,5 & $7.4 \pm 0.4$ & $6.2 \pm 0.1$ & NI* & NI* \\
\hline \multirow[t]{5}{*}{ Soxhlet } & 1000 & $9.4 \pm 0.9$ & $7.8 \pm 0.7$ & $6.2 \pm 0.1$ & $7.2 \pm 1.4$ \\
\hline & 500 & $7.9 \pm 1.1$ & $7.1 \pm 0.4$ & NI* & $6.2 \pm 0.1$ \\
\hline & 250 & $9.2 \pm 1.1$ & $6.5 \pm 0.1$ & NI* & $6.2 \pm 0.1$ \\
\hline & 125 & $7.3 \pm 1.2$ & $6.3 \pm 0.3$ & NI* & NI* \\
\hline & 62.5 & $7.2 \pm 1.2$ & $6.3 \pm 0.2$ & NI* & NI* \\
\hline \multirow[t]{5}{*}{ Fraction } & 1000 & $8.8 \pm 1.8$ & $8.6 \pm 04$ & $8.4 \pm 1.1$ & $8.1 \pm 0.1$ \\
\hline & 500 & $7.7 \pm 0.3$ & $7.1 \pm 0.2$ & $7.9 \pm 0.6$ & $7.1 \pm 0.3$ \\
\hline & 250 & $7.4 \pm 0.1$ & $6.8 \pm 0.1$ & $7.5 \pm 0.6$ & $7.0 \pm 0.3$ \\
\hline & 125 & $6.9 \pm 0.1$ & $6.6 \pm 0.1$ & $7.4 \pm 0.7$ & $6.7 \pm 0.3$ \\
\hline & 62.5 & $6,6 \pm 0,3$ & $6,3 \pm 0,1$ & $6,9 \pm 0,6$ & $6,5 \pm 0.5$ \\
\hline Standart & & $16.7 \pm 0.3$ & $15.7 \pm 0,6$ & $19.7 \pm 0.3$ & $17.7 \pm 0.6$ \\
\hline Control & & NI* & $\mathrm{NI}^{*}$ & NI* & $\mathrm{NI}^{*}$ \\
\hline
\end{tabular}

Control (10\% DMSO), Standard: Tetracyclin $(10 \mu \mathrm{g} / \mathrm{disc}),{ }^{*} \mathrm{NI}:$ No inhibition, Values were expressed as mean

\subsection{Analysis of Total phenolic and Flavonoid Compounds}

The amount of total phenolic in each extract was calculated as milligrams (mg) equivalent of gallic acid per gram of dry plant (mg GAE/g). In contrast, flavonoid content was calculated as milligrams (mg) equivalent of quercetin per gram of dry plant $(\mathrm{mg}$ QE/g). Gallic acid is the standard generally used for measurement of total phenolic, while quercetin standard is usually used for flavonoid content. The extraction method and various solvent used affected the total phenolic and flavonoid content obtained ${ }^{28}$. The total phenolic and flavonoid content obtained by the three extraction methods was presented in Table 7. Based on the analysis obtained that the phenolic content of $V$. amigdalina extracts varies according to the polarity solvent and the extraction method used. Besides, the extracts obtained by the fractionation method using ethyl acetate solvent showed the highest total phenols $28.83 \pm 2.62 \mathrm{mg}$ $\mathrm{GAE} / \mathrm{g}$ compared to other methods. Table 7 also shows that the flavonoid content of $\mathrm{V}$. amigdalina extracts varies according to the solvent and the extraction method used. The extraction using the maceration method with ethyl acetate solvent showed the highest flavonoid content $38.36 \pm 0.14$ compared to other methods. The content of flavonoid in the ethyl acetate with the maceration method is $38.36 \pm 0.14 \mathrm{mg} \mathrm{QE} / \mathrm{g}$.

Table 7. Total phenolic and flavonoids contents of extract Vernonia amigdalina.

\begin{tabular}{|c|c|c|c|c|c|c|}
\hline \multirow{2}{*}{ Sample } & \multicolumn{3}{|c|}{ Phenolic (mg GAE/g extract) } & \multicolumn{3}{c|}{ Flavonoids (mg QE/g extract) } \\
\cline { 2 - 7 } & Maceration & Soxhlet & Fraction & Maceration & Soxhlet & Fraction \\
\hline Ethanol & $7.59 \pm 0.05$ & $18.69 \pm 1.75$ & $14,10 \pm 0.07$ & $14.16 \pm 0,01$ & $31.97 \pm 0.01$ & $7.07 \pm 0.12$ \\
\hline $\begin{array}{c}\text { Ethyl } \\
\text { acetate }\end{array}$ & $18.90 \pm 0.54$ & $21.67 \pm 0.54$ & $28.83 \pm 2.62$ & $38.36 \pm 0.14$ & $11.20 \pm 0.01$ & $18.78 \pm 0.15$ \\
\hline
\end{tabular}

Phenolic and flavonoid compounds have been reported to have biological activities variety. Such as anticancer, antidiabetic, antihypertensive, antitumor, and including antioxidant properties ${ }^{29,30}$. The research showed that the extraction methods influence the yield percentage, the phenolic and flavonoid content of extract, and the antioxidant properties and antibacterial activity. Phenolic and flavonoid compounds of the $V$. amigdalina are 
allegedly responsible for the traditional use of this plant in diabetic treatment.

\section{Conclusion}

Extraction methods influence the yield percentage extract, antioxidant activity, total phenolic, and flavonoid; but, no significant influence at the antibacterial activity. Extraction using ethyl acetate solvent by fractionation method is the best method to find the antioxidant compounds of $\mathrm{V}$. amigdalina. The extracts of $\mathrm{V}$. amygdalina were categorized as providing moderate antibacterial activity against all bacteria test.

\section{Acknowledgments}

The authors are thankful to the Ministry of technology research and higher education Republic of Indonesia Directorate of research and community service. The latter has funded this research through grant Basic Research 2019 with contract No. 0057.04/UN9/SB3.LP2M.PT/2019. Thank also to the department of chemistry University of Sriwijaya on the facility for this research work.

\section{References}

1- J. B. Harborne, Phytochemical methods, $2^{\text {nd }}$ edition, ITB Bandung, 1987.

2- R. Marugan, J.P. Thangara, Comparative evaluation of different extraction method for antioxidant and anti-inflammatory properties from Osbeckia parvifolia Srn.-An in-vitro approach, Journal of King Saud UniversityScience, 2014, 26, 267-275.

3- A.B. Nursuhaili, A.S.P. Nur, M.Y.A. Martini, T.M.M. Mahmud, A Review: Medicinal values, Food Research, 2019, 3, 380-390.

4- J.J. Magadula, P. Erasto, Bioactive natural products derived from the East African flora, Natural Product Reports, 2009, 26,1535-1554.

5- Y. Zenebe, T. Garumma, W.K. Fand, Khat use in persons with mental illness in Southwest Ethiopia: a cross-sectional study, Journal of Addiction Research \& Therapy, 2015, 6, 2421-2425.

6- X. Luo, J. Yan, R.F. Frank, L. Cuiwu, B.I. Ernest, S.L. Ken, Isolation and structure determination of a sesquiterpene lactone (vernodalinol) from Vernonia amygdalina extracts, Pharmaceutical Biology, 2010, 49, 464-470.

7- A. Sinisi, E. Millan, S.M. Abay, A. Habluetzel, G. Appendino, E. Munoz, O. Taglialatela-Scafati, Poly-electrophilic sesquiterpene lactones from Vernonia amygdalina: New members and differences in their mechanism of thiol trapping and in bioactivity, Journal of Natural Products, 2015, 78, 1618-1623.

8- R. Bestari, M. Ichwa, Mustofa, D. Satria, Anticancer activity of Vernonia amygdalina Del. extract on WiDr colon cancer cell Line,
Advances in Health Sciences Research, 2018, 9,172-176.

9- W. Johnson, P. B. Tchounwou, C.G. Yedjou, Therapeutic Mechanisms of Vernonia amygdalina Delile in the Treatment of Prostate Cancer, Molecules, 2017, 22, 1594.

10-A.A. Adedapo, O. Ademola, J. A. lujoke, Antioxidant, anti-inflammatory and antinociceptive properties of the acetone leaf extract of Vernonia Amygdalina in some laboratory animals, Advanced Pharmaceutical Bulletin, 2014, 4, 591-8.

11-S. K. Yeap, W.Y. Ho, B.K. Beh, W.S. Liang, H. Ky, A. H. N. Yousr, N.B. Aitheen, Vernonia amygdalina, an ethnoveterinary and ethnomedical used green vegetable with multiple bioactivities, Journal Medicinal Plant Res., 2010, 4, 2787-2812.

12-G. O. Igile, O. Wieslaw, J. Marian, B. Stanislaw, F. Michael, A.F. Adetunde, Flavonoid from Vernonia Amygdalina and their antioxidant activities, Journal of Agricultural and Food Chemistry, 1994, 42, 2445-2448.

13-P. Erasto, D.S. Grierson, A.J. Afolayan, Bioactive sesquiterpene lactones from the leaves of Vernonia Amygdalina, Journal of Ethnopharmacology, 2006, 106, 117-120.

14-Indonesian Ministry of Health, Standard parameters of medicinal plant extracts. Jakarta, Indonesia: Indonesian FDA, 2000.

15-T. Dhanani, S. Shah, N.A. Gajbhiye, S. Kumar, Effect of extraction methods on yield, phytochemical constituents and antioxidant activity of Withania somnifera, Arabian Journal of Chemistry, 2017, 10, S1193-S1199.

16-A. Wanger, Disk diffusion, and gradient methodologies: antimicrobial respectability testing protocols, Editor: R. Schwalbe, L.SteeleMoore, A. C. Goodwin. Boca Raton: CRC Press, USA, 2007.

17-S. Chusri, C.I. Nattawan, T. Wanvalit, L. Surasak, P.V. Supayang, In vitro antibacterial activity of ethanol extracts of nine herbal formulas and its plant, components used for skin infections in Southern Thailand, Journal of Medicinal Plants Research, 2012, 6, 5616-5623.

18-M. Yangthong, T.M. Hutadilok, W. Phromkunthong, Antioxidant activities of four edible seaweeds from the southern coast of Thailand, Plant Foods Human Nutrition, 2009, 64, 218-223.

19-G.N. Sharma, Phytochemical screening and estimation total phenolic content in Aegle marmelos Seeds, International Journal of Pharmaceutical and Clinical Research, 2011, 2, 27-29.

20-J. Santoso, S. Anwariyah, R.O. Rumiantin, A.P. Putri, N. Ukhty, Y. Yoshie, Phenol Content, Antioxidant activity, and fibers profile of four tropical seagrasses from Indonesia, Journal of Coastal Development, 2012, 15, 189-196. 
21-C.C. Chang, M.H. Yang, H.M. Wen, J.C. Chern, Estimation of total flavonoid content in propolis by two complementary colorimetric methods, J. Food. Drug Anal., 2002, 10, 178-182.

22-I. Hassan, D. Konchock, S. Abdul, A. Parvaiz, Sunscreens and antioxidants as photo-protective measures: an update, Nasza Dermatologi online, 2013, 4, 369-374.

23-A. E. Nugroho, A. Malik, S. Pramono, Total phenolic and flavonoid contents, and in vitro antihypertension activity of purified extract of Indonesian cashew leaves (Anacardium occidentale L.), International Food Research Journal, 2013, 20, 299-305.

24-S. C. Quispe, M.A. Foglio, P.T.V. Rosa, M.A.A. Meireles, Obtaining b-caryophyllene from Cordia verbenacea de Candolle by supercritical fluid extraction, J. Supercrit. Fluids, 2008, 46, 27-32.

25-H. A. Hayouni, M. Abedrabba, M. Bouix, M. Hamdi, The effects of solvents and extraction method on the phenolic contents and biological activities in vitro of Tunisian Quercus coccifera L. and Juniperus phoenica L. fruit extracts, Food Chem., 2007, 105, 1126-1134.
26-P. Molyneux, The use of the stable free radicals diphenylpicrylhydrazyl (DPPH) for estimating antioxidant activity, Songklanakarin J. Sci. Technol., 2004, 26, 211-219.

27-W. W. Davis, T.R. Stout, Disc plate method of microbiological antibiotic Assay, Journal of Microbiology, 1971, 22, 666-670.

28-J. E. Karkouri, A. Drioiche, A. Soro, A. Ailli, N. Benhlima, A. Bouzoubaa, F.E. Makhoukhi, H. Oulhaj, F.K. Elombo, T. Zair, Identification and antioxidant activity of Ammi visnaga $L$. polyphenols from the Middle Atlas in Morocco, Mediterr.J.Chem., 2020, 10, 649-658.

29-K. A. Kang, M.J. Piao, S. Ryu, Y.J. Hyun, J.E. Park, K. Shilnikova, H.K. Zhen, Y.S. Kang, Y.J. Koh, J.W. Jeong, J.W. Hyun, Luteolin induces apoptotic cell death via antioxidant activity in human colon cancer cells, Int. J. Oncol., 2017, 51, 1169-1178.

30-M. Maatouk, N. Mustapha, I. Mokdad-Bzeouich, H. Chaaban, B. Abed, I. Iaonnou, K. Ghedira, M. Ghoul, J.C.T. Ghedira, Thermal Treatment of luteolin-7-O--glucoside Improves Its Immunomodulatory and Antioxidant Potencies, Cell Stress Chaperones, 2017, 22, 775-785. 